\title{
A ORIGEM MÍTICA DO REI DO BAIÃO NA LITERATURA DE CORDEL
}

\author{
Harlan Teixeira Parente*
}

\begin{abstract}
RESUMO: Este trabalho que surgiu do desejo de compreender Luiz Gonzaga segundo a visão da Literatura de Cordel. Este trabalho teve como objetivo analisar as representações dadas pelos cordelistas sobre a figura de Luiz Gonzaga. Usamos como fontes privilegiadas a literatura de cordel que versa sobre o músico. Também utilizamos documentos públicos, livros e músicas ligadas ao artista. Busquei realizar uma discussão teórico-metodológica pautado nos estudos da História Cultural que pretende entender as representações sociais sobre os eventos. No artigo analiso as representações da infância e da juventude de Gonzaga.
\end{abstract}

PALAVRAS-CHAVES: História cultural; Luiz Gonzaga; Música.

\section{The mystic origin of the King of the Baião in cordel's literature}

ABSTRACT: This work had as objective to analyze how representations given by the cordelistas on a figure of Luiz Gonzaga. We used as privileged sources the cordel literature that deals about the musician. It also uses public documents, books and songs linked to the artist. I searched for a theoretical-methodological discussion based on the studies of Cultural History that intends to understand as social representatives about the events. In the article I analyze like representatives of the childhood and the youth of Gonzaga.

KEYWORDS: Cultural history; Luiz Gonzaga; Music.

\section{El origem mítico del Rey del Bahón em La literatura de cordel}

RESUMEN: Este trabajo que surgió del deseo de comprender Luiz Gonzaga según la visión de la Literatura de Cordel. Este trabajo tuvo como objetivo analizar las representaciones dadas por los cordelistas sobre la figura de Luiz Gonzaga. Usamos como fuentes privilegiadas la literatura de cordel que versa sobre el músico. También utilizamos documentos públicos, libros y canciones vinculadas al artista. Busqué realizar una discusión teórico-metodológica pautado en los estudios de la Historia Cultural que pretende entender las representaciones sociales sobre los eventos. En el artículo analizo las representaciones de la infancia y la juventud de Gonzaga.

PALABRAS-CLAVE: Historia cultural; Luiz Gonzaga; música.

\footnotetext{
* Mestre e especialista em História pela Universidade Federal Rural de Pernambuco. Atualmente é professor do ensino público e privado desde 2003. Contato: Universidade Federal Rural de Pernambuco, Programa de PósGraduação em História, Rua Dom Manuel de Medeiros, s/nº , Prédio Professor Ariano Suassuna (1º Andar), Dois Irmãos, CEP: 52171-010, Recife, PE, Brasil. E-mail: harlanhtp@ hotmail.com.
} 


\section{O cordel como fonte para a Historiografia}

Até as primeiras décadas do século $\mathrm{XX}$ a historiografia valorizava apena a vida dos representantes das classes dominantes. As camadas sociais inferiores eram despercebidas pela História. Havia a preocupação com a busca da "verdade" no momento da coleta das informações para a reconstituição dos fatos, o historiador buscava testemunhas oculares, nos casos em que não podia registrar o que ele mesmo vira ${ }^{1}$.

A partir do século XX a historiografia sofreu mudanças significativas com a criação da Escola dos Annales que aproximou as pesquisas históricas a outras ciências sociais como a antropologia, a psicologia e a sociologia, possibilitando enfatizar a história dos sujeitos comuns e não comuns. Peter Burke afirma que este movimento tinha o intuito de promover uma nova espécie de história que teria como objetivos essenciais a substituição da tradicional narrativa de acontecimentos pela busca de uma história-problema, e a valorização de todas as atividades humanas frente à história política ${ }^{2}$.

Apenas no início da década de 1960 é que os historiadores sociais emprenharam-se em buscar as vozes das camadas populares. Esse período de renovação foi denominado por Jacques Le Goff e outros historiadores por "Nova História" para se referir aos novos rumos para a escrita da história ${ }^{3}$.

Ginzburg opta pela perspectiva da cultura popular ao invés dos componentes racionais de visões do mundo ${ }^{4}$. Para Bakhtin, existe uma circularidades entre as camadas superiores e as classes subalternas por meio de influências recíprocas que se movem de baixo para cima, bem como de cima para baixo ${ }^{5}$.

Foi final da década de 1960 e início da década de 1970, com estas mudanças ocorridas no fazer historiográfico, que a literatura de cordel finalmente adentrou no campo dos trabalhos históricos. Antes visto pelos historiadores como mera fricção e relato literário de um período, com a virada cultural, essa literatura torna-se bem aceita nos meios acadêmicos, período em que a História passa a dialogar diretamente com a Literatura.

Hayden White defende essa aproximação entre a História e a Literatura ao argumentar que o historiador poderia ser visto como alguém que procura explorar uma perspectiva do mundo que não pretende esgotar a descrição ou a análise. Para White, mesmo que mesmo que consigamos fazer distinções entre História e ficção, ainda assim o texto do historiador será a escrita daquilo que o passado poderia consistir, trazendo a historiografia para mais perto de suas origens na sensibilidade literária, seremos "capazes de identificar o elemento ideológico, porque fictício, contido no próprio discurso". 6 
Segundo Mark Curran, o cordel trata-se de uma crônica popular por expressar a visão do povo nordestino. Seus poetas são do povo e o representam nos seus versos. São também, além de jornalistas, conselheiro do povo e historiador popular ${ }^{7}$. Grillo afirma que os folhetos traduzem notícias da imprensa da capital para a linguagem do habitante do sertão, muitas vezes mudando e dando novos significados às informações ${ }^{8}$.

O primeiro cordel escrito sobre Luiz Gonzaga que se tem notícia é o do poeta e compositor José Praxedes publicado no início da década de 1950, período que o sanfoneiro estava no auge do sucesso nacional. Nestes folhetos, assim como nos versos de outros cordelistas, o sanfoneiro é bastante elogiado, um predestinado à fama que enfrentou grandes dificuldades, mas que com seu grande talento e persistência alcançou o sucesso com suas músicas, seus trajes e discursos, buscando representar sua terra de origem, o sertão nordestino. Praxedes conheceu Luiz Gonzaga pessoalmente na época do lançamento do seu cordel quando ambos moravam no Rio de Janeiro, principal cidade política e cultural do país do período, onde atuavam na esfera artística.

Uma parte dos cordeis aqui citados foram publicados no ano do centenário de nascimento de Luiz Gonzaga, em 2012, período em que as homenagens eram mais marcantes e o imaginário popular em torno do sanfoneiro era mais evidente, incentivando a publicação de diversos tributos, incluindo a publicação de diversos cordeis. Dentre os cordelistas citados neste período temos José Medeiros de Lacerda, Edson Massilon Matias e Paulo de Tarso.

\section{O contexto histórico brasileiro no período do nascimento do mito Luiz Gonzaga}

No ano de 1946, período em que Luiz Gonzaga inicia seu período de sucesso, o Brasil vivia uma fase de certo otimismo e liberdade por conta de acontecimentos políticos marcantes. O país acabara de sair de uma ditadura que perdurava por quase uma década que ficou conhecida por Estado Novo e tinha como governante Getúlio Vargas. ${ }^{9}$ Era o fim de um período de contradição, pois o país apoiava o bloco de nações que combatiam as ditaduras europeias como a Alemanha nazista e a Itália fascista, e ao mesmo tempo usava mecanismos de torturas, prisões, assassinatos e perseguições.

Sobre este momento, a cientista política Eli Diniz afirma:

Nesse momento, é a figura do Vargas ditador que assume o primeiro plano, a imagem do homem que, através de um golpe de Estado, com o auxílio das Forças Armadas, instaura a ditadura, pondo fim à breve e turbulenta experiência democrática de 1934-37, traindo assim os ideais da revolução de que fora um dos principais líderes. Nesse momento, domina a cena o Vargas identificado com o ideário autoritário. Durante esse período, dá-se continuidade à produção da extensa 
legislação trabalhista e previdenciária, que regularia o trabalho urbano durante as várias décadas de desenvolvimento da industrialização por substituição de importações. ${ }^{10}$

Outro acontecimento marcante para o período foi a promulgação de uma nova Constituição que teve como dispositivos principais a liberdade de todos perante a lei, a liberdade de manifestação de pensamento, a liberdade de consciência, de crença e de cultos religiosos. A Constituinte de 1946 é um campo fértil para se pensar as diversas possibilidades de interpretação do tempo histórico, bem como a relação entre História e Memória. Segundo João Almino ${ }^{11}$ aquele era o momento de repensar e reformular os fundamentos sobre os quais se assentava o velho edifício carcomido e começar tudo de novo, liberando as energias criadoras reprimidas e colocando-as a serviço da regeneração do organismo enfermo. Pensar a Constituinte de 1946 é pensar a noção de tempo: um passado que precisava ser julgado e punido; um presente que exigia urgência de soluções; um futuro que depositava todos os sonhos libertários; futuro "democrático" em que todos os brasileiros seriam livres. O presente era um tempo intermediário entre a ditadura e a democracia, a função do "agora" era resolver os problemas sociais e econômicos do país para que, assim, o futuro se tornasse presente.

O Rio de Janeiro, a Capital Federal, recebia um grande contingente de migrantes nordestinos desde meados da década de 1930 que buscavam na cidade grande, em plena expansão urbano-industrial, uma vida melhor, fugindo da seca que assolava a região. Segundo Conceição Almeida ${ }^{12}$, essas viagens eram feitas muitas vezes em "pau-de-arara ${ }^{13}$ " e duravam em média de quinze a vinte dias. Quando às vezes passavam fome, os migrantes eram jogados em uma esquina qualquer, sem orientação e encaminhamento para emprego, ou seja, quando não suportavam a falta de uma alimentação mínima para a sobrevivência, eram abandonados na estrada antes de chegarem ao destino final e teriam que procurar alguma forma de viver em condições precárias.

Durval Muniz afirma que:

(...) milhares de homens pobres do campo foram obrigados a deixar seu local de nascimento, suas terras, para migrarem em direção ao Sul, notadamente São Paulo e Rio de Janeiro para onde iam em busca de empregos, na pujante agricultura comercial, mas sobretudo, no parque industrial que, a partir da Primeira Guerra, se desenvolve aceleradamente ${ }^{14}$

No ambiente cosmopolita do Rio de Janeiro ocorreram duas novidades nas primeiras décadas do século XX, a descoberta do teatro de revista ${ }^{15}$, que conjugava música, humor e mulheres bonitas, e a evolução da radiofonia ${ }^{16}$. Melhorariam também os meios de transportes e os meios de comunicação, principalmente a presença do rádio como o grande veículo de 
comunicação de massa desde a década de trinta, que estimulava a migração de nordestinos através de propagandas do governo e de instituição interessadas em mão-de-obra. O rádio vai ser pensado como veículo de integração nacional e capaz de produzir e divulgar uma cultura nacional ${ }^{17}$.

Até o início da década de 1930, as emissoras de rádio divulgavam em seus programas músicas eruditas. Mas a partir de 1932, com a implantação de um decreto presidencial ${ }^{18}$ que obrigava a mídia a divulgar propaganda comercial, o rádio transformou-se em veículo popular voltado para o lazer e a diversão ${ }^{19}$. No período do governo de Getúlio Vargas, ocorreu uma busca pela modernização do país que incluía o rádio e a indústria do disco. O rádio tornou-se um meio de comunicação de massa poderoso, pois teve:

(...) capacidade de falar simultaneamente a incontáveis milhões, cada um deles sentindo-se abordado como indivíduo, transformava-o numa ferramenta inconcebivelmente poderosa de informação de massa, como governantes e vendedores logo perceberam, para propaganda política e publicidade. ${ }^{20}$

“O desenvolvimento do rádio criava espaço para a diversidade musical, as emissoras, como a Rádio Nacional, tinham orquestras sinfônicas e regionais. Elas vão se constituir em polos de atração para manifestações artísticas, agregando músicas de várias áreas do país"21. A música que até então era considerada apenas de caráter erudito, adquire nova importância com a música produzida pelas camadas populares num momento em que a produção cultural e artística é redefinida como a preocupação com o popular e com o nacional.

A Rádio Nacional ganhou expressividade e se tornou uma poderosa ferramenta da música popular, sobretudo para o repertório gonzagueano. Segundo Lia Cabrale, “em 12 de setembro de 1936, a Rádio Nacional do Rio de Janeiro fez sua primeira transmissão oficial. A emissora pertencia ao mesmo grupo que produzia a revista A Noite Ilustrada, Carioca e Vamos Ler, além da editora S. A. Rio e do jornal A Noite. Esses veículos de comunicação faziam parte dos empreendimentos do capitalista norte-americano Percival Faquhar. Para Cabrale "A Nacional permaneceu reconhecidamente, como emissora de maior penetração e audiência por todo o país na era de ouro do rádio". 22

Foram construídos nos anos 1930 enormes estúdios com auditórios que apresentavam os programas de calouros que atraíam diversas pessoas para verem de perto seus ídolos. ${ }^{23} \mathrm{O}$ começo da carreira artística de Luiz Gonzaga no mercado fonográfico coincidiu com a implantação do Estado Novo e com a expansão radiofônica no país. Em 1940, Getúlio Vargas incorporou ao Patrimônio da União, através do decreto-lei nº 2.073, ferrovias, terras e rádios, 
dentre elas a Nacional. Foi no auditório da Rádio Nacional que Luiz Gonzaga divulgou o baião e ganhou maior notoriedade. ${ }^{24}$

\title{
A infância e a fuga de Exú
}

Luiz Gonzaga do Nascimento nasceu em 13 de dezembro de 1912, na fazenda Caiçara, em Exú ${ }^{25}$, Pernambuco. Esta região está localizada na Serra do Araripe. ${ }^{26}$. Filho de Januário José dos Santos e Anna Baptista de Jesus, conhecida como Santana ${ }^{27}$ em homenagem a Nossa Senhora de Santana, venerada no sertão. ${ }^{28}$

O primeiro cordelista que versou sobre a vida de Luiz Gonzaga foi José Praxedes Barreto, conhecido como Zé Praxedi. ${ }^{29} \mathrm{O}$ poeta descreve sobre o nascimento de Gonzaga no cordel intitulado Luiz Gonzaga, publicado em 1952 nas página 6 e 7:

\author{
Meu nome é Luiz Gonzaga \\ Não sei se sou fraco ou forte \\ Sei que graças a Deus \\ Té pra nascer tive sorte \\ Apôs nasci em Pernambuco \\ Famoso Leão do Norte \\ Nas terra de Nôvo Exu \\ Da fazenda Caiçara \\ Im novecentos e dôse \\ Viu o mundo minha cara \\ Dia de Santa Luzia \\ Purisso é qui sô Luiz \\ No mêz que Cristo nasceu \\ Purisso é que sô feliz \\ Lá nas terras im que nasci \\ Só tem valor o vaqueiro \\ O home pra sê liberto \\ Precisa sê cangaceiro \\ Mas meu pai, Graças a Deus \\ È um grande sanfoneiro
}

Neste cordel, o nascimento de Gonzaga é representado como um momento de felicidade, o canto é visto como uma pessoa que teve sorte na vida, inclusive por ter nascido em um estado valente, Pernambuco, conhecido como Leão do Norte. O cordelista afirma que na sua terra o vaqueiro é valorizado, porém submisso ao dono das terras; para ser livre é preciso ser cangaceiro, pegar em armas. Porém Gonzaga preferiu seguir outro destino, ser um grande sanfoneiro igual ao pai.

Segundo dos nove filhos do casal Januário e Santana, Luiz Gonzaga criou gosto pela sanfona com o pai que tocava nas festas e que serviu de inspiração para construir sua carreira 
na música. Luiz Gonzaga descreve em entrevista dado ao jornal $O$ Globo em março de 1972 que vivia no Pé de Serra nas feiras, ajudando a vender com sua mãe cordas de caroá ${ }^{30}$.

No folheto O Nascimento de um rei”, nas páginas 9 e 10 produzido no ano de 2012, o cordelista José Medeiros de Lacerda ${ }^{31}$ representa a infância de Gonzaga do seguinte modo:

\author{
Aquela criança amada \\ Poderia se tornar \\ Um jagunço do patrão \\ Como era de se esperar \\ E assim seria feliz \\ Mas o menino Luiz \\ Nascera para cantar \\ Sempre aos pais a ajudar \\ Com uma enxada na mão \\ Luiz Gonzaga crescia \\ Na maior animação \\ Mas também acompanhava \\ O pai quando este atuava \\ Em sua outra profissão
}

No cordel, Luiz Gonzaga é representado como uma criança trabalhadora, que ajuda os pais no roçado, sua vida era ligada ao mundo rural. Também remete a paixão pela música que herdou do seu pai, considerado por pessoas de sua região como um exímio tocador e consertador de sanfona. Nos versos vemos que Gonzaga não seguiu o ofício de outros que viviam na mesma região: ser jagunço do patrão que significava trabalhar armado como segurança do senhor das terras. A predestinação para ser músico como seu pai está evidenciada nos versos.

O escritor Roniwalter Jatobá afirma que Gonzaga era um menino de roça que cresceu "solto nos matos da Chapada do Araripe". Plantava, caçava, pescava e tirava leite de cabra para ajudar no sustento da família. Não tinha acesso a escola nem a livros. Só comia carne nos fins de semana quando vendia com sua mãe cordas na feira da cidade. ${ }^{32}$ Essas análises permitem observar a infância humilde que remete as condições de vida comuns da gente pobre do sertão de Pernambuco. A vida precária na infância influenciou o cantor em sua trajetória artística através das letras de suas canções que muitas vezes denunciavam as mazelas sofridas pelos seus conterrâneos. Luiz Gonzaga é representado como "homem do povo" pelo seu público e pelos cordelistas em razão deste discurso bastante recorrente em seu repertório musical.

$\mathrm{Na}$ adolescência, Gonzaga fazia sucesso nos bailes tocando sua sanfona, atraindo a atenção das moças da região. Uma delas era filha de um fazendeiro rico que não aprovava o relacionamento com o sanfoneiro por este pertencer a uma classe social inferior. Gonzaga 
conta em entrevista ao jornal O Globo, do Rio de Janeiro do dia 8 de setembro de 1972: "eu tocava forró e namorei uma moça rica. O pai dela, Raimundo Deolino, quando soube me chamou de sanfoneiro atrevido de meia tigela e sem futuro. E eu cheguei a querer matá-lo. A sorte foi a surra que minha mãe me deu."

De acordo com este depoimento Gonzaga se mostrava um jovem pobre, trabalhador e valente, ao ponto de desafiar um coronel que o tinha desdenhado. Segundo ele, a interferência da mãe por meio de uma surra evitou uma desavença mais séria. Em entrevista a Gildson Oliveira $^{33}$ poucos meses antes de sua morte, no ano de 1989, o artista afirma que após o desentendimento, o coronel Raimundo foi a procura de sua mãe, Santana, e disse que só não matara seu filho por consideração a sua família. Desde o século XIX o coronel representava uma figura autoritária e poderosa, seu prestígio podia ser medido pela rede de relações que mantinha com as pessoas. Influenciava em eleições, nos preenchimentos de cargos públicos e em nomeações políticas. Esses coronéis eram protegidos e protegiam homens conhecidos por jagunços ou capangas. ${ }^{34}$

Este acontecimento culminou na partida de Luiz Gonzaga de sua terra natal para a cidade do Crato onde vendeu sua sanfona e viajou para Fortaleza para se alistar ao exército em 1929.

Edson Massilon Matias, cordelista nascido em Tauá, interior do Ceará, em 6 de julho de 1935, foi funcionário dos Correios e Telégrafos, se destacando na época como um grande telegrafista, quando as mensagens ainda eram passadas através desse meio de comunicação. Depois se tornou um poeta transformando em versos as paisagens e os destaques do interior do Ceará.

O poeta narrou nas páginas 2 e 3 do folheto $O$ Gonzagão da Sanfona a fuga de Gonzaga da cidade de Exú, publicado em 2012:

\author{
Como todo "cabra macho" \\ teve sua primeira paixão \\ os seus dezessete anos \\ faziam dele um vulcão \\ desejando o casamento \\ com uma "branca" do sertão" \\ Tolinho no seu intento \\ recebeu grande desfeita \\ e, partiu para vingança \\ por sua mãe não aceita \\ dela levou uma surra \\ para acabar com a despeita! \\ Fugiu de casa pro Crato \\ sua sanfona vendeu
}


foi de trem pra Fortaleza

onde o Exército o acolheu

participou da revolta

que em São Paulo aconteceu

Nesses versos vemos que aos dezessete anos Luiz Gonzaga teve sua primeira paixão que faziam dele um vulcão. O desejo pela moça era intenso, os arroubos do amor o levou a desafiar um poderoso coronel local. O resultado dessa afronta foi uma surra que levou da mãe ao ser alertada pelo fazendeiro sobre o "desvio de conduta do filho" que o poderia levar à morte. Gonzaga decidiu abandonar sua terra por conta deste acontecimento que marcou sua vida e é bastante representado pelos cordelistas.

O preconceito sofrido por Gonzaga também é evidenciado pelo cordelista ao afirmar que o artista foi rejeitado por Raimundo, pai de sua paixão Nazinha, por ser pobre e se apaixonar por uma senhorita branca. Mas ao final do cordel, Luiz Gonzaga vira o herói que participa da "revolta que em São Paulo aconteceu"35, ou seja, ainda que tenha saído de Exú para não ser morto, ele foi para a guerra. Nesses versos vemos que mesmo uma cena triste, uma derrota clara, o abandono da amada e de sua terra, Gonzaga é representado como um bravo que vai para a luta.

\section{E Gonzaga sai do sertão}

Durante o Estado Novo Gonzaga morou em vários lugares do Brasil. Após passar um período na cidade mineira de Juiz de Fora, em maio de 1937 foi transferido para a cidade de Ouro Fino, na Serra da Mantiqueira. Foi neste local que, segundo o historiador Paulo Donizéti o artista aprimorou sua arte com o exímio acordeonista José Mainardi e se apresentou pela primeira vez em um palco, no Éden Clube. Foi nesse paraíso que o soldado Nascimento ficou para trás e surgiu definitivamente o sanfoneiro Luiz Gonzaga.O sonho de infância havia retornado, o sanfoneiro percebeu que a música deveria ser o seu destino pois não saía de sua mente este momento marcante da sua vida, a primeira exibição em um tablado. ${ }^{36}$

Após passar a década de 1930 servindo ao exército, viajando pelo Brasil afora e conhecendo diversas regiões e culturas variadas, Gonzaga teve que deixar o Exército. Existia um decreto que proibia os soldados de se engajarem por um período superior a dez anos. $\mathrm{O}$ seu tempo nas forças armadas estava com os dias contados. Durante este período militar, ficou conhecido como o "bico de aço" por tocar muito bem a corneta, instrumento utilizado nos cerimoniais dos quarteis. 
O poeta Zé Praxedi narra a vida militar de Gonzaga no seu cordel Luiz Gonzaga, nas páginas 6 e 7, publicado em 1952:

\author{
Cum o meu disimbaraço \\ Consiguí na capitá \\ Sentá praça im poucos dias, \\ No izerço naçioná \\ E nas filêra do Izerço \\ Sempre mostrei sê nortista \\ Num tive superiô \\ Para andá im minha pista \\ Nunca dexei de sê home \\ Im quarqué ponto de vista \\ No ano de trinta e nove \\ Fui obrigado a deixá, \\ O culégio do fi di póbe \\ O Izerço Naçioná.
}

O poeta retrata Gonzaga como um soldado valente, que não temia o trabalho nem os seus superiores, pois ele era um homem forte por ser nortista. Para o cordelista, o exército era o colégio do filho de pessoas pobres e Gonzaga se incluía nesta classe social. Mas foi no Rio de Janeiro, após sair das fileiras do exército que ele conseguiu iniciar a vida como músico profissional. Foi na capital federal, maior centro de divulgação musical do país, que Gonzaga se dedicou exclusivamente à música.

No dia 27 de março de 1939, Gonzaga embarcou num trem para o Rio de Janeiro com uma passagem de navio para o Recife e um passe de trem que o levaria até Exú, além de um dinheiro para as despesas e uma ordem de permanência provisória num quartel do Rio, no Batalhão de Guardas, onde aguardaria a chegada ao navio Lloyd no qual devia embarcar. ${ }^{37}$

Luiz Gonzaga ficou no quartel esperando a viagem de volta a sua terra natal. Amedrontado pela agitação da cidade, mesmo já tendo passado uma época no lugar como militar não a conhecia bem, ficou trancado e passava o tempo tocando e limpando a sanfona. Um soldado o convidou para conhecer o Mangue que ficava próximo ao local de sua hospedagem onde poderia ganhar dinheiro enquanto não chegava o dia do retorno ao sertão. O ambiente era frequentado por beberrões, soldados, marinheiros, boêmios, malandrões, mendigos e ladrões. O mangue fervilhava com bares lotados e inferninhos. A maioria dos bares tinha seus conjuntos e os músicos que não conseguiam um ponto tocavam nas ruas a espera de gorjetas. No dia seguinte após a primeira visita ao lugar, Gonzaga levou sua sanfona para o local e se atirou na vida musical.

João Batista Ferreira Lima foi um importante cordelista, nascido em São José do Egito, Pernambuco, em 1902. Autor de um importante almanaque popular nordestino, o 
Almanaque de Pernambuco, lançado em 1936, e que entre 1936 e 1972 alcançou uma tiragem de mais de 70.000 exemplares. Percorreu vários temas da poesia popular, privilegiando as Discussões e Pelejas. Publicou Discussão de dois poetas, Antônio da Cruz com Cajarana e Peleja de João Athayíde com João Lima, do qual temos conhecimento de duas edições: uma de Recife, de 1921 e outra, de Juazeiro do Norte, em 1957. Também abordou os temas de malandragem e presepada, cuja obra mais conhecida é As palhaçadas de João Grilo, folheto de 8 páginas, em sextilhas que, em 1948, foi ampliada por João Martins de Ataíde para 32 páginas sob o título de Proezas de João Grilo.

Este poeta transformou em versos a passagem da vida de Gonzaga para as apresentações nos mangues cariocas no cordel intitulado Vida e morte de Luiz Gonzaga: o rei do baião, publicado no ano de 1994, na página 4:

Depois que Luiz deu baixa
do Exército Brasileiro
enfrentou dificuldade
lá no Rio de Janeiro
tocava em qualquer lugar
a fim de arranjar dinheiro
Tocava em qualquer lugar
não escolhia o ambiente
tocou no café do mangue
usando chapéu na frente
venceu porque era forte
corajoso e competente

O cordel mostra a transição na vida de Gonzaga quando deixou o quartel e passou a fazer apresentações no mangue carioca. Após um início com dificuldades para sobreviver, o artista conseguiu o sucesso por ser um homem forte, corajoso e competente que tocava em qualquer lugar a fim de ganhar dinheiro e de ser reconhecido. Estes versos contam da bravura do homem, não da qualidade ou do estilo da música. Este era um tema bastante evidenciado pelos cordelistas, o sujeito sertanejo valente.

Segundo José Ramos Tinhorão, no período da segunda guerra mundial, de 1939 a 1945, era grande a presença de marinheiros de outros países no Rio de Janeiro. As músicas tocadas na Capital Federal eram dominadas por ritmos estrangeiros como o tango, a valsa, os boleros, as polcas, as mazurcas. ${ }^{38} \mathrm{O}$ samba-canção, bastante influente na época, foi se modificando e passou a ser confundido com o bolero, tornando-se distante de suas origens mais remotas. ${ }^{39}$

De início, Gonzaga se apresentava no Rio de Janeiro recebendo toda a carga da influência estrangeira exercida na região. Do seu repertório faziam parte fados, valsas e 
foxtrotes. $^{40}$ Trajava paletó e gravata e tocava as músicas estrangeiras para conseguir sobreviver. Em suas noites de trabalho fez várias amizades, dentre elas com o baiano Xavier Pinheiro em 1940, ex-marinheiro e músico da rádio Vera Cruz, com quem formou uma dupla e que o convidou para morar em sua casa no morro de São Carlos. Gonzaga desistiu de voltar para Exú após sua permissão para continuar no quartel expirou. ${ }^{41}$ Xavier tornou-se um protetor e mestre que ensinou os truques da vida de músico e boêmio.

Passavam os meses, Gonzaga ia se tornando mais autônomo, fechava seus contatos musicais com mais facilidade. Procurou Anteógenes Silva, um famoso acordeonista conhecido como o "mago do acordeom" para lhe ensinar tango, ritmo bastante executado na região. Para divulgar seu nome, procurou se apresentar nos programas de calouro das rádios cariocas. Os mais famosos eram o Papel Carbono, de Renato Murce, e o Calouros em Desfile, de Ary Barroso, que ia ao ar às tardes de domingo na rádio Tupi, onde os calouros se apresentavam e tentavam reconhecimento que era obtido com a nota máxima cinco dada pelo apresentador e pelos jurados. Nas primeiras exibições nestes programas Gonzaga não conseguia nota superior a três. ${ }^{42}$

\title{
O encontro com os universitários
}

Em uma das apresentações no mangue, Gonzaga recebeu um desafio de um grupo de jovens universitários cearenses ${ }^{43}$ que estudavam no Distrito Federal, seria tocar "as coisas lá do Norte."

Em entrevista a Dreyfus, o cantor explicou esse importante contato com os seus conterrâneos:

\begin{abstract}
Gonzaga tentou argumentar que as músicas do Sertão ele aprendera a tocar num fole mixuruca, que não tinha nada a ver com a sanfona dele; que essa música não ia interessar aos fregueses dos bares onde ele costumava tocar. Mas os cearenses implicaram e ameaçaram não botar mais moedas no pires do sanfoneiro se ele não tocasse uma coisinha lá do Nordeste. Gonzaga acabou prometendo que na próxima vez, ele tocaria alguma coisa lá daqueles pés de serra. ${ }^{44}$
\end{abstract}

Uma semana após o desafio o sanfoneiro retornou ao local da apresentação para mostrar algumas músicas que ele tinha treinado para executar. Segundo o relato do próprio Luiz Gonzaga: "Sapequei as músicas. Antes de chegar à mesa deles, o pires, estava cheio, troquei por ouro prato, que também encheu, peguei uma bandeja. Eu tinha descoberto o mapa da mina." $" 45$

Um poeta que retrata esse momento da vida de Luiz Gonzaga é Paulo de Tarso, cordelista cearense nascido em 1963 na cidade de Tauá. Professor de história que começou a 
versar a partir de um trabalho na escola e não parou mais de escrever. Publicou aproximadamente noventa cordéis, um livreto e dois CDs de poesias populares. Em seu cordel intitulado $O$ Gonzagão Centenário, publicado em 2012, o poeta versou nas páginas 7 e 8 sobre o encontro de Gonzaga com os estudantes:

\author{
Recebeu um desafio \\ De uns cabras do Ceará: \\ E já no próximo encontro \\ Você só receberá \\ Uma gorjeta descente \\ Tocando coisas de lá \\ Entre esses estudantes \\ Estava Armando Falcão, \\ Um jurista reconhecido \\ Que repetiu o refrão: \\ Quero ver você tocar \\ Cantigas lá do sertão \\ O grupo ali retornou \\ Para ouvir Gonzagão. \\ Gonzaga tocava polcas, \\ Mas nada lá do sertão. \\ E, de olho nos sujeitos \\ Mudou a sua versão \\ Sapecou foi Pé de Serra, \\ Onde a sanfona se abria. \\ Todo o público, em delírio, \\ Ao grande mestre aplaudia. \\ E o dinheiro foi tanto \\ Que derramou da bacia
}

Os versos acima mostram um momento importante na vida do sanfoneiro quando desafiado pelos universitários cearenses a tocar "coisas de lá". Entendendo este "lá" como o sertão de onde partiram estes estudantes, o próprio Gonzaga e outros inúmeros migrantes que tinham saudade dos lugares onde nasceram e passaram a sua infância, e desejavam escutar algo que lhes recordassem as suas origens.

Gonzaga é representado como uma pessoa inteligente e talentosa que conseguiu atender ao pedido dos estudantes e que na primeira experiência recebeu um bom trocado, o pires encheu de tanto dinheiro recebido. Para Luiz Gonzaga, esse foi um momento de reflexão e de mudança de direção. ${ }^{46}$ Gonzaga encontraria a fórmula da trilha do sucesso.

\title{
O rádio e o cantor
}

Após o episódio envolvendo o encontro com os estudantes cearenses, Luiz Gonzaga decidiu participar novamente do programa de Ary Barroso e tentar uma sorte melhor, pois das 
outras vezes não alcançara a nota máxima. Iria mudar o repertório no intuito de melhorar o conceito frente ao novo julgamento.

Era uma manhã de domingo. Como sempre, o amplo auditório da rádio Tupi estava repleto de gente jovem e bonita. Na primeira fila, o severo corpo de jurados, tendo como destaque o saudoso cantor e radialista Almirante. No palco, a austera figura de Ari Barroso que, ao anunciar o nome do sanfoneiro, foi logo cobrindo-o de leves gracejos:

-Então, seu Luiz Gonzaga, qual é a valsinha que vamos ouvir dessa vez?

-Apresentarei, se o senhor permitir, uma música de minha autoria chamada Vira e mexe ${ }^{47}$

Naquele dia o Vira e mexe fez virar o auditório da radio Tupi e mexeu tanto com os sentimentos dos jurados, que Luiz Gonzaga saiu dali ovacionado com a nota máxima. "Saí pra comemorar a vitória", diz Gonzaga, "fui comer pão doce com refresco de maracujá num boteco próximo". Depois do êxito alcançado no programa de Ari Barroso, Gonzaga passou a frequentar vários outros programas radiofônicos. ${ }^{48}$

O êxito obtido por Gonzaga no programa de calouros rendeu um cordel publicado por

\section{Zé Praxedi em 1952, denominado Luiz Gonzaga:}

Havia lá na Tupi

Um programa caprichoso

Mêrmo num se sendo artista

O sujeito corajoso

Vinha morrê nas garra

Do sinhô Arí Barrôso

Eu chegava me incostando

Lá no parco da Tupi

E munto discunfiado:

Bôas noite, seu Arí!

E, assim fui muntas vês

Sem as nota amiorá,

As musga de minha terra

Eu num pudia tocá...

Só éra musga qui vinha

Do outro lado do má.

-Bôas noite, seu Barrôso!

-Rapaz, procure um imprêgo

-Seu Arí, me dê licença

Pra eu tocar um chamego?

-Chamêgo? O quí é isso

No rol da coisa mundana?

-O Chamêgo, seu Barrôso

$\mathrm{E}$, musca pernambucana

Nota cinco. Nesse dia

Dêxei a musga estrangeira

Passei de musgo sufrive

A bom musgo, de prenmêra!

E pude vê qui quí no Rio

Tinha gente brasileira 
O cordelista representa Luiz Gonzaga como um sujeito corajoso, persistente e desconfiado diante do exigente comandante do programa radiofônico Ari Barroso. Após algumas tentativas, o artista conseguiu atingir a nota máxima pela primeira vez após tocar músicas regionais em vez de ritmos estrangeiros executados anteriormente. As portas para o sonhado reconhecimento estavam se abrindo

Esta ótima passagem pelo programa Calouros em Desfile rendeu a Luiz Gonzaga um bom dinheiro, mas o sanfoneiro almejava um impulso maior para conseguir atingir o sucesso. Trabalhar em um programa de rádio na época era um importante passo para crescer na carreira. Em um encontro no mangue com Zé do Norte, cantor que trabalhava em dois programas na rádio Tupi, Gonzaga pediu uma ajuda para trabalhar em alguma emissora. $\mathrm{O}$ pedido foi atendido, pouco tempo depois foi convidado para trabalhar com o amigo na Rádio Transmissora, futura Rádio Globo, no programa A Hora Sertaneja. Sobre o fato, Dreyfus afirma:

A temática sertaneja das músicas apresentadas no programa correspondia exatamente ao que Gonzaga fazia de melhor. Ele conhecia bem o repertório regional paulista, mineiro, nordestino. Os cinco mil réis que ganhava por programa, quando muito, pagava o bonde e uma cerveja. Mas Gonzaga tocaria até de graça, desde que integrasse uma estação de rádio, como era o caso. Sabia que podia fazer nome, tornar-se conhecido dos profissionais do planeta radiofônico. No limiar da década de 40, o sanfoneiro do Araripe sabia aonde queria chegar, e como tinha que agir para conseguir chegar. ${ }^{49}$

Neste período, início da década de 1940, havia espaço para a diversidade musical por conta do desenvolvimento do rádio. As emissoras possuíam suas orquestras e seus conjuntos regionais. Gonzaga estava trilhando um caminho para o sucesso. Passou a ser conhecido no meio musical local. A gravação de duas músicas com o cantor paulista Genésio Arruda na gravadora Victor rendeu-lhe um contrato em 1941 para registrar agora suas próprias músicas. Neste ano, Gonzaga teve suas primeiras gravações realizadas, era mais um sonho conquistado no caminho para a consagração. A Segunda Guerra Mundial que ocorria nesta época trouxe ao Brasil famosos escritores exilados, as notícias da guerra que se desenrolavam principalmente na Europa tomavam parte dos noticiários das rádios. Foi nesse contexto histórico que Gonzaga viu sua carreira decolar.

Luiz Gonzaga passou a trabalhar como sanfoneiro também em outros programas de rádios com temáticas regionais como o Alma do Sertão apresentado por César e Alencar, na Rádio Clube e depois na Mayrink Veiga e na Tamoio.

Com o reconhecimento artístico em fase embrionária, Gonzaga inicia suas apresentações nos melhores dancings, clubes e cinemas do Rio de Janeiro onde se arriscava 
como cantor após declarar que havia saturado de ser apenas instrumentista e por entender que cantar era o caminho mais curto entre o anonimato e a fama ${ }^{50}$.

Em 1943, Gonzaga faz sua primeira temporada fora da Capital Federal, foram 45 dias tocando em Curitiba onde foi bem recebido pela crítica local. Voltando ao Rio de Janeiro, o artista fracassou inicialmente no desejo de cantar nos programas de rádio e em gravações ${ }^{51}$. Decidiu então ceder suas músicas para outras pessoas cantarem, mas desistiu da empreitada de ser apenas compositor. Ameaçou sair da gravadora Victor, onde mantinha um vínculo apenas como instrumentistas, caso não o deixassem gravar como cantor. $\mathrm{O}$ diretor artístico Vitório Lattari cedeu ao desejo do pernambucano de Exú para não perdê-lo para a concorrente Odeon que aceitaria realizar o sonho de Luiz Gonzaga. Em 11 de Abril de 1945, Gonzaga cantou sua primeira música, a mazurca "Dança Mariquinha" 52 , de sua autoria em parceria com Miguel Lima. No mesmo ano, gravou o chamego "Penerô Xerém." 53 Assim, foi contratado para a Rádio Nacional onde entrou no rol dos artistas conceituados.

Um importante cordelista que versou sobre Gonzaga foi João Firmino Cabral. Ele nasceu em 1940, em Itabaiana, Sergipe. Filho de Pedro Firmino Cabral, cantador de feira e embolador, e de Cecília da Conceição, roceira. Foi agricultor desde menino, quando começou a demonstrar interesse pelas letras. Comprava então folhetos de Literatura de Cordel, que usava como cartilha, pois com eles aprendeu a ler. Aos 17 anos, com o auxílio do seu mestre, o poeta Manoel D'Almeida Filho, descobriu sua vocação poética e escreveu seu primeiro folheto, Uma Profecia do Padre Cícero. Daí por diante não parou de versar. Em Aracajú, viveu exclusivamente da Literatura de Cordel, mantendo a única banca fixa de folhetos cordelianos de Sergipe, localizada na Passarela das Flores do Mercado Antônio Franco, onde frequentemente recebia poetas sergipanos e de outros Estados, como também estudantes, professores, pesquisadores e turistas do Brasil e do mundo. Escreveu diversos folhetos educativos a pedido de escolas e entidades públicas e privadas. Proferiu palestras em diversas instituições de ensino. Em 2002, foi agraciado com a medalha do Mérito Cultural Serigy, concedida pela Prefeitura Municipal de Aracaju. Em 2003, foi escolhido como patrono da $1^{\text {a }}$ Cordelteca do Brasil, que funciona na Biblioteca Pública Municipal Clodomir Silva, em Aracajú. Em 2008 tomou posse na ABLC, na cadeira 36, patronímica de Expedito Sebastião da Silva. O poeta João Firmino morreu em decorrência de problemas causados por leucemia, em 1 de fevereiro de 2013, em Aracaju. ${ }^{54}$

No folheto Luiz Gonzaga o Rei do Baião, publicado em 1992, o cordelista versou nas páginas 6 e 7 do seguinte modo o momento citado da vida do autor: 


\author{
Porem antes da cidade \\ Passou uma vida dura \\ Percorrendo Realengo \\ Corcovado e Cascadura \\ Procurando qualquer galho" \\ Pra ele qualquer trabalho \\ Era uma boa aventura \\ Mas depois descobriu que \\ Tinha uma voz excelente \\ Pegou cantar nas boates \\ Aguardando a muita gente \\ Por uns era criticado \\ Por outros era vaiado \\ Porém tocou para frente \\ Depois começou cantar \\ Para animar o São João \\ Algumas marchas juninas \\ Nos forrós da região \\ Como foi grande o sucesso \\ Daí foi tendo o ingresso \\ Para o reino do baião \\ Comprou logo uma sanfona \\ E um grande chapéu de couro \\ Fez do baião o seu reino \\ Da sanfona o seu tesouro \\ O Nordeste o consagrou \\ O povo o denominou \\ "Luiz Gonzaga de Ouro"
}

O cordel acima representa Luiz Gonzaga como um vencedor na carreia após passar por dificuldades financeiras e por tentar cantar, pois era criticado por diretores de rádios e por parte do público por não ter uma voz bonita. Mas para o cordelista, Gonzaga tinha uma excelente voz e como era persistente e talentoso, conseguiu obter êxito em sua empreitada.

O cordel mostra também o sucesso que suas músicas alcançaram e que se identificam bastante com o período de São João. O baião tornou-se referência musical de uma região, estilo musical que se fortalece no período junino. No trecho do verso 'um grande chapéu de couro', o cordelista mostra uma peça da indumentária usada pelo artista para representar o vaqueiro, figura típica do sertão nordestino.

Segundo Assis Ângelo, o artista tinha grande vontade se der cantor, e não apenas instrumentista. O motivo era porque este seria o caminho mais curto entre o anonimato e a fama. $^{55}$ 


\section{Considerações Finais:}

O interesse por parte dos historiadores com relação à literatura de cordel tem aumentado consideravelmente nas últimas décadas. A análise do mesmo tem enriquecido a história com a valorização da cultura popular e de seus artistas. Luiz Gonzaga foi bastante mencionado nesses livretos que o representavam em geral como um legítimo representante da cultura nordestina. O sanfoneiro é mostrado como o artista que expressa pelas letras de suas canções o cotidiano do sertão nordestino, nos momentos ruins de seca e fome e nos momentos alegres nas festas e em épocas de festejos.

Os cordelistas foram importantes para a criação da imagem mítica de Gonzaga quando retratavam o artista como um heroi que sobreviveu à fome e a infância pobre, assim como muitos dos seus conterrâneos,e alcançou o sucesso nacional cantando a vida difícil do sertanejo, não esquecendo de suas origens.

Penso que esse artigo, centrado na história cultural poderá trazer contribuições para o enriquecimento da historiografia ao abordar a cultura popular pela análise da literatura de cordel e da figura de Luiz Gonzaga, um artista de origem popular que se mostrava representante dos seus conterrâneos pelos seus discursos e suas músicas.

\section{Notas}

${ }^{1}$ REIS, José Carlos. A História: entre a filosofia e a ciência. Belo Horizonte. Autêntica.2006.

${ }^{2}$ BURKE, Peter. Escola dos Annales(1929-1989) : a Revolução Francesa da Historiografia. São Paulo: UNESP, 1997,p.16.

${ }^{3}$ LE GOFF, Jacques. La Nouvelle Historie. Paris. Retz, 1978.

${ }^{4}$ GINZBURG, Carlo. O queijo e os vermes. São Paulo: Cia das Letras, 1987.

${ }^{5}$ BAKHTIN, Mikhail. A cultura popular na Idade Média e no Renascimento. São Paulo/Brasília: Hucitec/UNB, 1987.

${ }^{6}$ WHITE, Hayden. Trópicos do discurso:Ensaio Sobre a Crítica da Cultura. São Paulo: Editora da USP, 1994. p.46-47.

${ }^{7}$ CURRAN, Mark. História do Brasil em cordel. São Paulo: EDUSP, 1994. p.46-47.

${ }^{8}$ GRILO, Maria Ângela de Faria. A arte do povo: Histórias na literatura de cordel (1900-1940). Tese de doutorado em História Social-UFF-RJ. Niteroi. 2005. p.89.

${ }^{9}$ FAUSTO, Boris. História do Brasil. Editora da Universidade de São Paulo, 1994.

${ }^{10}$ Ver: DINIZ, Eli. Engenharia institucional e políticas públicas: dos conselhos técnicos às câmaras setoriais. In: PANDOLFI, Dulce. Repensando o Estado Novo. Rio de Janeiro: Ed. Fundação Getúlio Vargas, 1999, p.23.

${ }^{11}$ Ver: ALMINO, João. Os Democratas Autoritários. São Paulo: Brasiliense, 1980.

${ }_{12}$ ALMEIDA, Conceição. Coisas do Arco da Velha, Jornal A República, Natal, 17/08/1979.

${ }^{13}$ Pau de arara é o nome dado a um meio de transporte irregular e ainda utilizado no interior do Nordeste. Consiste em adaptar caminhões para o transporte de passageiros, constituindo-se em substituto improvisado para os ônibus convencionais. Foi bastante usado para a migração de nordestinos rumo ao Sudeste durante o século $\mathrm{XX}$.

${ }^{14}$ ALBUQUERQUE JÚNIOR, Durval Muniz de. A Invenção do Nordeste e outras artes. São Paulo: Cortez, 2009, p.171.

${ }^{15}$ Teatro de Revista é gênero teatral bastante popular na primeira metade do século XX. Era um espaço onde se dava um franco diálogo com o mundo da música popular. Afinal, com a popularização do teatro de revista e a 
ausência de meios de divulgação de peso, como um mercado discográfico e radiofônico forte, a colocação de músicas em peças era uma chance importante para um compositor ou cantor popularizar seus produtos. Sobre essa discussão ver GOMES, Tiago de Melo. "Gente do samba: malandragem e identidade nacional no final da Primeira República."Topoi, Rio de Janeiro (2004): p.171-198.

${ }^{16}$ SAROLDI, Luiz Carlos e MOREIRA, Sonia Virginia. Rádio Nacional - O Brasil em sintonia. Rio de Janeiro: Jorge Zahar Editora, 2006, p.23.

${ }_{17}$ ALBUQUERQUE JÚNIOR, Durval Muniz de. Op. cit. p.172.

${ }^{18} \mathrm{O}$ decreto de lei $\mathrm{n}^{\mathrm{o}} 21.111$ assinado pelo presidente Vargas em $1^{\circ}$ de marco de 1931 autorizava as emissoras de rádio a realizarem propaganda eleitoral. Esta lei associada ao aumento do número de emissora de rádios na década de 1930 acarretou na mudança da forma de atuação das rádios, pois possibilitou uma maior divulgação da música popular. Ver. SATOS, José Farias do. Luiz Gonzaga: a música como expressão do Nordeste. São Paulo: Editora Ibrasa, 2004.p.31-32.

${ }^{19}$ FERRETI, Mundicarmo. Baião de Dois: Zé Dantas e Luiz Gonzaga. Recife: Massangana,1998, p.61.

${ }^{20}$ HOBSBAWN, Eric J. Era dos Extremos: o breve século XX (1914-1991). São Paulo: Companhia das Letras, 1995.p.194-195.

${ }^{21}$ ALBUQUERQUE JÚNIOR, Durval Muniz de. A Invenção do Nordeste e outras artes. São Paulo: Cortez, 2009 , p. 171.

${ }^{22}$ CABRALE, Lia. A Era do Rádio. $2^{a}$ ed. Rio de Janeiro: Jorge Zahar Editor, 2004, p.30-32.

23 MORAES, Jonas Rodrigues de. MORAES, Jonas Rodrigues de. Sons do sertão: Luiz Gonzaga, música e identidade. Annablume, 2012. p.24.

${ }^{24}$ SAROLDI, Luiz Carlos e MOREIRA, Sonia Virginia. Rádio Nacional: O Brasil em sintonia. Rio de Janeiro: Jorge Zahar Editora, 2006. p.54.

${ }^{25}$ A cidade de Exú fica na região oeste de Pernambuco, quase divisa entre os estados de Ceará e Pernambuco, no alto sertão. Fica a seiscentos quilômetros de distância tanto do Recife quanto de Fortaleza. O povoado de Araripe onde nasceu Luiz Gonzaga fica a doze quilômetros do centro da cidade. O nome Exú é uma corruptela do nome da tribo ançu, da nação indígena dos cariris, primeiros habitantes da região. Acredita-se também na versão de que na região existiam muitas abelhas denominadas inxú. Ver. ECHEVERRIA, Renata. Gonzaguinha e Gonzagão: uma história brasileira. São Paulo: Ediouro, 2006, p.21.

${ }^{26}$ A Chapada do Araripe nasce na Paraíba (...) e vai morrer na fronteira de Pernambuco com o Piauí. Sua inclinação drena todas as águas pendentes para o vale do cariri, região mais nobre e rica do Ceará, zona de cultivo de cana-de-açúcar e da rapadura. Ver: DREYFUS, Dominique. Vida de viajante. A saga de Luiz Gonzaga. São Paulo: Ed.34, 1996.p.27.

${ }^{27}$ BARBOSA, José Marcelo Leal. Luiz Gonzaga: cem anos do eterno rei do baião. Fortaleza: Design Editorial, 2012 , p. 15.

${ }^{28}$ ECHEVERRIA, Renata. Gonzaguinha e Gonzagão: uma história brasileira. São Paulo: Ediouro, 2006.p.22.

${ }^{29}$ Zé Praxedi nasceu em 1916 na cidade de Angicos, no estado do Rio Grande do Norte. Era também compositor, intérprete, escritor, radialista e jornalista. Foi morar no Rio de Janeiro em 1954 e no ano seguinte fez junto com Luiz Gonzaga uma memorável apresentação no Teatro Copacabana, no Rio de Janeiro, com o patrocínio do presidente João Café Filho.

${ }^{30}$ Coroá é uma planta resistente e típica das áreas da Caatinga. As folhas do caroá fornecem fibras para a confecção de barbantes, linhas de pesca, tecidos, cestos, esteiras e chapéus, além de outras peças artesanais e decorativas. Luiz Gonzaga compôs a música Arrancando Caroá em 1941. Luiz Gonzaga. Arrancando caroá. Choro, 78 RPM. RCA Victor 34768/B, 1941.

${ }^{31}$ O cordelista José Medeiros de Lacerda, paraibano de Santa Luzia, é autor, dançarino de teatro e professor de Letras, filho de José Aureliano Lacerda e Joana Edeltrudes de Medeiros. O poeta, neto de um holandês que era casado com uma portuguesa, começou a escrever os primeiros versos aos oito anos. Percorre o Brasil dando palestras e fazendo oficinas de xilogravura nas escolas. Escreveu mais de trezentos folhetos de cordel divididos em séries, tais como, Adivinhações, Caçadores, Cangaceiros, Bíblicos, Teatro e Política.

32 JATOBÁ Roniwalter. O jovem Luiz Gonzaga. São Paulo: Editora Nova Alexandria, 2012, p.19-22.

${ }^{33}$ OLIVEIRA, Gildson. Luiz Gonzaga: um matuto que conquistou o mundo. Recife: Editora Comunicarte,2000, p. 18 .

34 Os coronéis eram homens que tinham posses de terras nas cidades interioranas que após o fim da Guarda Nacional criaram uma rede de poder que envolvia o mandonismo local e o protecionismo aos parentes e empregados. Sua função deixou de ser associado ao militarismo da Guarda Nacional para se destacar como chefe político das vilas e das cidades menores. Ver: OLIVEIRA JÚNIOR, Rômulo José F. de. Antônio Silvino: de governador dos sertões a governador da detenção (1875-1944) Dissertação de mestrado em História Social da Cultura Regional- UFRPE. Recife. 2010, p.42

35 A Revolução Constitucionalista de 1932, Revolução de 1932 ou Guerra Paulista, foi o movimento armado ocorrido no Estado de São Paulo entre os meses de julho e outubro de 1932, que tinha por objetivo a derrubada 
do governo provisório de Getúlio Vargas e a promulgação de uma nova constituição para o Brasil. Ver discussão em: CALMON, Pedro. O movimento constitucionalista. Rio de Janeiro: José Olympio, 1963, p. 37.

${ }^{36}$ SIEPIERKSI, Paulo Donizéti. Entrevista à Rádio Difusora da cidade de Ouro Fino, MG.

${ }^{37}$ JATOBÁ, Roniwalter. Op. cit. p.76

${ }^{38}$ ALBUQUERQUE JÚNIOR, Durval Muniz de. Op. cit. 174.

${ }^{39}$ TINHORÃO, José Ramos. Pequena História da Música popular: da modinha à canção de protesto. Rio de Janeiro. Vozes, 2013. p.125.

${ }^{40}$ ARLEGO, Edvaldo. Luiz Gonzaga:centenário do Rei do Baião. Recife:Editora Edificantes, 2012,p.19.

${ }^{41}$ MOTA,José Fábio. Luiz Gonzaga: O Asa Branca da Paz. Sobral: UVA, 2001,p.14.

${ }^{42}$ Idem.p.79-80

${ }^{43}$ Dentre o grupo de estudantes estava Armando Falcão que se tornaria ministro da Saúde na presidência de Jânio Quadros em 1961 e ministro da Justiça nos governos de Juscelino Kubitschek e Ernesto Geisel. No governo militar, foi o artífice da Lei Falcão que limitou drasticamente o acesso dos políticos ao rádio e a televisão. Foi citado no álbum de Luiz Gonzaga "Volta Pra curtir" de 1972 como presidentes da República de Estudantes na qual Luiz Gonzaga fora convidado a tocar.

${ }^{44}$ DREYFUS, Dominique. Vida de viajante: A saga de Luiz Gonzaga. São Paulo: Ed.34, 1996.

${ }^{45}$ Depoimento de Luiz Gonzaga, disponível no álbum "O melhor de Luiz Gonzaga: melodias cifradas para guitarras, violão e teclados”. São Paulo: Irmãos Vitale, 2000.p.10.

${ }_{46}^{4}$ ECHEVERRIA, Renata. Op. Cit. p.46.

${ }^{47}$ Luiz Gonzaga. Vira e mexe. Chamego, solo de sanfona (instrumental). 78 RPM. RCA Victor, 334748/B, 1941.

${ }^{48}$ FERREIRA, José de Jesus. Luiz Gonzaga: o Rei do Baião: sua vida, seus amigos, suas canções. São Paulo: Ática, 1996, p.32.

${ }^{49}$ DREYFUS, Dominique. Op. Cit. p.87

${ }^{50}$ JATOBÁ, Roniwalter. Op. Cit.p.90.

${ }^{51} \mathrm{O}$ artista foi proibido de cantar na rádio Tamoio a mando do diretor Fernando Lobo que não gostava da voz de Gonzaga, depois tentou gravar na Victor e foi barrado por Vitório Lattari.

${ }^{52}$ Luiz Gonzaga e Miguel Lima. Dança Mariquinha. Mazurca. DREYFUS, Dominique. Vida de viajante. A saga de Luiz Gonzaga. São Paulo: Ed.34, 1996. Victor 80.0281 a, gravação 11/04/1945

${ }_{53}$ Luiz Gonzaga e Miguel Lima. Penerô Xerém. Victor 800306 a, gravação 13/06/1945.

${ }^{54}$ Sobre a biografia do cordelista João Firmino ver: http:/www.nordeste.com/onordeste/enciclopediaNordeste. Acesso em 06 de julho de 2015.

55 ÂNGELO, Assis. Dicionário Gonzagueano, de A a Z. São Paulo: Editora Parma, 2006,p.36.

\section{Referências Bibliográficas:}

ALBUQUERQUE JÚNIOR, Durval Muniz de. A Invenção do Nordeste e outras artes. São Paulo: Cortez, 2009.

ALMINO, João. Os Democratas Autoritários. São Paulo: Brasiliense, 1980

ARLEGO, Edvaldo. Luiz Gonzaga:centenário do Rei do Baião. Recife:Editora Edificantes, 2012.

BAKHTIN, Mikhail. A cultura popular na Idade Média e no Renascimento. São Paulo/Brasília: Hucitec/UNB, 1987.

BURKE, Peter. Escola dos Annales(1929-1989) : a Revolução Francesa da Historiografia. São Paulo: UNESP, 1997.

CABRALE, Lia. A Era do Rádio. 2aed. Rio de Janeiro: Jorge Zahar Editor, 2004.

CALMON, Pedro. O movimento constitucionalista. Rio de Janeiro: José Olympio, 1963.

CURRAN, Mark. História do Brasil em cordel. São Paulo: EDUSP, 1994.

DREYFUS, Dominique. Vida de viajante: A saga de Luiz Gonzaga. São Paulo: Ed.34, 1996. ECHEVERRIA, Renata. Gonzaguinha e Gonzagão: uma história brasileira. São Paulo: Ediouro, 2006.

FAUSTO, Boris. História do Brasil. Editora da Universidade de São Paulo, 1994. 
FERREIRA, José de Jesus. Luiz Gonzaga: o Rei do Baião: sua vida, seus amigos, suas canções. São Paulo: Ática, 1996.

FERRETI, Mundicarmo. Baião de Dois: Zé Dantas e Luiz Gonzaga. Recife: Massangana,1998.

GINZBURG, Carlo. O queijo e os vermes. São Paulo: Cia das Letras, 1987.

GRILO, Maria Ângela de Faria. A arte do povo: Histórias na literatura de cordel (1900-1940). Tese de doutorado em História Social -UFF-RJ. Niteroi. 2005.

HOBSBAWN, Eric J. Era dos Extremos: o breve século XX (1914-1991). São Paulo: Companhia das Letras, 1995.

JATOBÁ Roniwalter. O jovem Luiz Gonzaga. São Paulo: Editora Nova Alexandria, 2012. LE GOFF, Jacques. La Nouvelle Historie. Paris. Retz, 1978.

MORAES, Jonas Rodrigues de. MORAES, Jonas Rodrigues de. Sons do sertão: Luiz Gonzaga, música e identidade. Annablume, 2012.

MOTA,José Fábio. Luiz Gonzaga: O Asa Branca da Paz. Sobral: UVA, 2001,p.14

OLIVEIRA, Gildson. Luiz Gonzaga: um matuto que conquistou o mundo. Recife: Editora Comunicarte, 2000.

OLIVEIRA JÚNIOR, Rômulo José F. de. Antônio Silvino: de governador dos sertões a governador da detenção (1875-1944) Dissertação de mestrado em História Social da Cultura Regional- UFRPE. Recife. 2010.

PANDOLFI, Dulce. Repensando o Estado Novo. Rio de Janeiro: Ed. Fundação Getúlio Vargas, 1999.

REIS, José Carlos. A História: entre a filosofia e a ciência. Belo Horizonte. Autêntica.2006.

SAROLDI, Luiz Carlos e MOREIRA, Sonia Virginia. Rádio Nacional: O Brasil em sintonia. Rio de Janeiro: Jorge Zahar Editora, 2006.

TINHORÃO, José Ramos. Pequena História da Música popular: da modinha à canção de protesto. Rio de Janeiro. Vozes, 2013.

WHITE, Hayden. Trópicos do discurso:Ensaio Sobre a Crítica da Cultura. São Paulo:

Editora da USP, 1994. 